\title{
Lung function 5 yrs after allogeneic bone marrow transplantation conditioned with busulphan and cyclophosphamide
}

\author{
M.B. Lund*, L. Brinch\#, J. Kongerud*, J. Boe*
}

Lung function 5 yrs after allogeneic bone marrow transplantation conditioned with busulphan and cyclophosphamide. M.B. Lund, L. Brinch, J. Kongerud, J. Boe. (C)ERS Journals Ltd 2004.

ABSTRACT: Long-term data on lung function after bone marrow transplantation (BMT) are inconclusive. Previously, a persistent reduction in gas transfer $1 \mathrm{yr}$ after allogeneic BMT with busulphan and cyclophosphamide conditioning was reported by the current authors. In the present study this reduction was examined to see if it was permanent, transient or progressive.

Prospectively, 43 consecutive adult patients with malignant blood disorders undertook lung function measurements prior to BMT, at 3 month intervals during the 1st yr after BMT and finally after 5 yrs.

Mean baseline lung function values were $>90 \%$ predicted. Within the 1 st yr after BMT a transient decline in lung volumes and a persistent reduction in gas transfer were observed. After 5 yrs, baseline values were restored for all variables, except in four patients who developed obliterative bronchiolitis. Acute leukaemia and smoking were independently associated with gas transfer reductions at baseline and during the 1st yr after BMT.

Allogeneic bone marrow transplantation with busulphan and cyclophosphamide conditioning was associated with a reduction in gas transfer $1 \mathrm{yr}$ after bone marrow transplantation but baseline values were usually restored after 5 yrs. Since recovery may be gradual and slow, an observation period $>1 \mathrm{yr}$ is required before drawing conclusions concerning the development of a permanent reduction in lung function after allogeneic bone marrow transplantation conditioned with busulphan and cyclophosphamide.

Eur Respir J 2004; 23: 901-905.
*Dept of Respiratory Medicine, Division of Heart and Lung Diseases, and "Section of Haematology, Medical Dept, The National Hospital, University of Oslo, Norway.

Correspondence: J. Boe

Dept of Respiratory Medicine

Division of Heart and Lung Diseases

The National Hospital

University of Oslo

$\mathrm{N}-0027$ Oslo

Norway

Fax: 4723073917

E-mail: jacob.boe@klinmed.uio.no

Keywords: Allogeneic

bone marrow transplantation

busulphan

cyclophosphamide

long term

pulmonary function

Received: July 222003

Accepted after revision: February 22004
Since therapeutic success has resulted in a growing number of long-term survivors after allogeneic bone marrow transplantation (BMT), the risk of delayed adverse effects has become a matter of concern $[1,2]$. Lung disease, as a cause of early morbidity and mortality following BMT, has been extensively described [3-6]. However, few studies have focused on long-term lung function in adult BMT survivors [7-10]. Furthermore, such studies have often been limited by heterogeneous patient groups [7-9], and short periods of observation $(<5$ yrs $)$ [7-10].

The term "late-onset noninfectious pulmonary complications" has been introduced to describe a syndrome of lung injury occurring $>3-6$ months after BMT $[8,11]$. The pathogenesis of this syndrome is unclear but may be related to conditioning regimens given prior to BMT, immunosuppressive therapy following BMT, or to the development of chronic graft versus host disease (GVHD) [8, 11, 12]. In malignant diseases, late toxicity due to previous conventional treatment (chemotherapy and irradiation) may also be of importance.

Cytoreductive therapy with high-dose busulphan (BU) and cyclophosphamide (CY) is an alternative to conditioning regimens that include total body irradiation (TBI) [13, 14]. However, both BU and CY are potentially toxic to the lung and may induce interstitial pneumonitis and subsequent pulmonary fibrosis [15]. Methotrexate and cyclosporine, which are commonly used as prophylactic agents against GVHD, have also been associated with adverse pulmonary effects [15]. Furthermore, bone marrow recipients are at risk of developing obliterative bronchiolitis (OB) usually associated with GVHD [16].

In Norway, all allogeneic BMT operations are performed in The National Hospital, University of Oslo. The patient population is recruited from the entire country, referred and selected according to uniform criteria and subjected to standardised treatment procedures. Conditioning with BU/ CY prior to BMT is the standard cytoreductive treatment for malignant blood disorders and TBI is not applied. In a previous, short-term lung function study by the present authors, allogeneic BMT with BU/CY was found to be associated with a persistent reduction in gas transfer $1 \mathrm{yr}$ after therapy [17]. In the present study, the authors aimed to assess long-term lung function in the same nonirradiated patient population conditioned with BU/CY according to a standard protocol. The present study was specifically undertaken to find out whether the observed impairment in gas transfer, $1 \mathrm{yr}$ after BMT would be permanent, transient or progressive after an extended observation period of 5 yrs.

\section{Material and methods}

Study subjects and design

A total of 65 adult patients underwent allogeneic BMT at the National University Hospital, Oslo, Norway, during 1990-1995, and were consecutively enrolled into a prospective 
study. The patients ( 37 males and 28 females, aged median (range) 33 (17-54) yrs) represented a national cohort, which were referred and selected according to uniform criteria, and had been subjected to standardised treatment prior to BMT. Each patient was examined on six occasions: prior to BMT; at $\sim 3$ months intervals during the 1st yr after BMT; and finally, after 5 yrs. Five patients, transplanted for nonmalignant blood disorders and given conditioning regimens without BU, were excluded from the study. Altogether, 17 patients were lost before the 5-yr follow-up examination. A total of $12 \mathrm{had}$ died (five within the first year), none of them from pulmonary complications (10 malignant relapse, one GVHD and one suicide). Five patients who were followed-up at regional hospitals for geographical reasons, were all reported to be healthy and without pulmonary complaints. The remaining 43 patients, who all completed the 5-yr follow-up, were included in the study. Their characteristics at inclusion are outlined in table 1 .

\section{Transplantation procedures}

Conditioning prior to BMT has previously been described $[14,17]$. Briefly, all patients were treated with BU orally at a dose of $1 \mathrm{mg} \cdot \mathrm{kg}^{-1}$ of body weight, four times daily for four consecutive days followed by $\mathrm{CY}$ at a daily dose of $60 \mathrm{mg} \cdot \mathrm{kg}^{-1}$ administered i.v. over a period of $30 \mathrm{~min}$ for two consecutive days [14]. Bone marrow was infused 2 days after the final dose of CY. No patients received TBI. GVHD prophylaxis consisted of methotrexate (i.v. on day 1, 3, 6 and 11) and cyclosporine. After stable engraftment, Trimetoprimsulpha-methoxazol was given as prophylaxis against Pneumocystis carinii infection. Chronic GVHD was diagnosed according to defined criteria [18].

Table 1. - Baseline clinical characteristics of 43 consecutive patients with malignant blood disorders treated with bone marrow transplantation and busulphan/cyclophosphamide conditioning

\begin{tabular}{lc}
\hline Sex M:F & $25: 18$ \\
Age yrs & $34(17-54)$ \\
Diagnosis & 29 \\
CML & 9 \\
AML & 3 \\
ALL & 2 \\
MDS & \\
Donor & 32 \\
Sibling & 11 \\
Unrelated & \\
Smoking & 28 \\
Nonsmoker & 2 \\
Exsmoker & 13 \\
Current smoker & \\
Lung function & $108 \pm 15$ \\
FVC \% pred & $103 \pm 13$ \\
FEV1 \% pred & $81 \pm 7$ \\
FEV1/FVC \% & $88 \pm 17$ \\
TL,CO \% pred & $94 \pm 15$ \\
TL,CO-Hb \% pred & $12.9 \pm 2.1$ \\
Hb g.100 mL ${ }^{-1}$ &
\end{tabular}

Data are presented as $\mathrm{n}$, median (range) or mean $\pm \mathrm{SD}$. M: male; F: female; CML: chronic myeloid leukaemia; AML: acute myeloid leukaemia; ALL: acute lymphocytic leukaemia; MDS: myelodysplastic syndrome; FVC: forced vital capacity; FEV1: forced expiratory volume in one second; \% pred: per cent predicted; $T \mathrm{~L}, \mathrm{CO}$ : transfer factor of the lung for carbon monoxide; $\mathrm{TL}, \mathrm{CO}-\mathrm{Hb}$ : transfer factor of the lung for carbon monoxide corrected for haemoglobin level; Hb: haemoglobin.

\section{Clinical and radiological evaluation}

All patients underwent clinical examination and had chest radiographs taken before BMT and at each of the six followup consultations. If acute respiratory infections coincided with the scheduled times of follow-up, lung function testing was postponed until the patient was free from signs and symptoms of infection. All chest radiographs were evaluated by two radiologists and a consensus was obtained.

\section{Lung function measurements}

Lung function tests included dynamic spirometry and gas diffusion capacity. Spirometry was performed with a watersealed spirometer. Gas transfer was measured by the single breath technique. All measurements were performed with the Gould automated system 2400 (Sensormedics BV, Bilthoven, Netherlands) according to guidelines recommended by the American Thoracic Society [19, 20]. Registered variables were forced vital capacity (FVC), forced expiratory volume in one second (FEV1), FEV1/FVC x 100 (FEV1/FVC ratio) and the transfer factor of the lung for carbon monoxide $(T \mathrm{~L}, \mathrm{CO})$. All $T \mathrm{~L}, \mathrm{CO}$ values were adjusted for haemoglobin $(\mathrm{Hb})$ concentration by using the correction formula recommended by COTES et al. [21]. The Hb-levels were obtained on the same day as the lung function testing. Since the correction of $T \mathrm{~L}, \mathrm{CO}$ for alveolar volume ( $V \mathrm{~A})$ did not influence the results of the analyses, the variable $T \mathrm{~L}, \mathrm{CO} / V \mathrm{~A}$ is not reported. The lung function variables were expressed in absolute values and as percentage of predicted [22]. To assess longitudinal changes in lung function, values for FVC, FEV1 and transfer factor of the lung for carbon monoxide corrected for haemoglobin level $(T \mathrm{~L}, \mathrm{CO}-\mathrm{Hb})$ were expressed as a percentage of their baseline values. Complete recovery of lung function was defined as an improvement to $>90 \%$ of baseline values. OB was defined as post-BMT development of irreversible airflow obstruction characterised by both FEV1 $<70 \%$ pred and FEV1/FVC $<70 \%$ [16].

\section{Statistics}

Categorical data were compared by the Chi-squared test. Group mean data were compared with the unpaired t-test. The t-test for paired data was used to compare lung function values pre-BMT with post-BMT at the time of maximum reduction (i.e. 3 months), at 1-yr follow-up and 5-yr followup. Bonferroni's correction was applied when multiple comparisons were carried out. In total four patients with OB were excluded from the longitudinal lung function analyses. Multiple linear regression was used to detect relationships between pulmonary function and relevant independent covariates. Variables with more than two categories were transformed into binary variables. Chronic myeloid leukaemia (CML) and myelodysplastic syndrome (MDS) were tested versus the acute leukaemias (i.e. $\mathrm{CML}+\mathrm{MDS}=1$ and otherwise $=0)$. Smokers were tested versus nonsmokers, with the two exsmokers excluded from the analyses. The independent variables entered into the regression models were those found to be significant at the $20 \%$ level by previous univariate analysis. A p-value $<0.05$ was considered to be statistically significant.

\section{Results}

All patients had normal chest radiographs at the time of inclusion. Pulmonary function for the entire study group was 
within the normal range. Baseline spirometric values were $>100 \%$ and gas transfer (Hb-adjusted) $>90 \%$ pred (table 1 ). Patients with acute leukaemias had significantly lower baseline $T \mathrm{~L}, \mathrm{CO}-\mathrm{Hb}$ (mean $\pm \mathrm{SD} \%$ pred) than patients with chronic leukaemia $(84 \pm 13 \%$ versus $96 \pm 14 \%, \mathrm{p}=0.02)$, and smokers had lower baseline $\mathrm{TL}, \mathrm{CO}-\mathrm{Hb}$ than nonsmokers $(87 \pm 13 \%$ versus $96 \pm 15 \%, \mathrm{p}=0.04)$. The effects of malignant disorder and smoking on $\mathrm{TL}, \mathrm{CO}-\mathrm{Hb}$ in a multiple linear regression model were analysed controlling for sex and age. The current authors found that the associations between $T \mathrm{~L}, \mathrm{CO}-\mathrm{Hb}$ and acute leukaemia and smoking persisted $(-12.3 \pm 4.1$ ( $\beta$ coefficient $\pm \mathrm{SE})$, $\mathrm{p}=0.005$, and $8.1 \pm 4.1, \mathrm{p}=0.05$, respectively).

Within the 1st yr after BMT, eight patients developed chronic GVHD. In total, four developed persistent airflow obstruction consistent with OB (fig. 1). These four patients were nonasthmatic nonsmokers with normal baseline lung function. After 5 yrs, two of the patients were clinically stable, while two had developed bronchiectasis, recurrent infections and chronic respiratory failure. One patient was on the waiting list for lung transplantation, while the other was still under assessment at the time of writing the current article.

In total, four patients with $\mathrm{OB}$ were excluded from the analyses. Table 2 shows lung function before BMT, and at 3

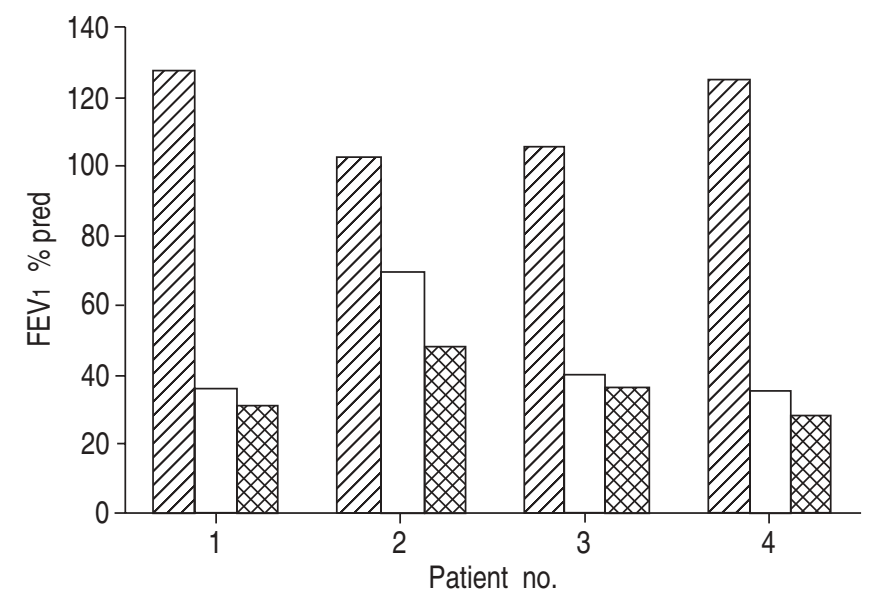

Fig. 1.- Forced expiratory volume in one second (FEV1) predicted before bone marrow transplantation (BMT), and $1 \mathrm{yr}$ and $5 \mathrm{yrs}$ after BMT in four patients who developed obliterative bronchiolitis. baseline; $\square 1 \mathrm{yr} ; 5 \mathrm{yrs}$.

Table 2.-Lung volumes, gas transfer and haemoglobin before and after bone marrow transplantation (BMT) in 39 consecutive patients with malignant blood disorders treated with BMT and busulphan/cyclophosphamide conditioning (patients with obliterative bronchiolitis excluded)

\begin{tabular}{lcccc}
\hline & Pre-BMT & 3 months & 12 months & 5 yrs \\
\hline FVC \% pred & $108 \pm 15$ & $99 \pm 17^{* * *}$ & $102 \pm 16$ & $109 \pm 16$ \\
FEV1 \% pred & $103 \pm 12$ & $96 \pm 13^{*}$ & $99 \pm 13$ & $102 \pm 13$ \\
FEV 1/FVC \% & $80 \pm 7$ & $84 \pm 8^{*}$ & $82 \pm 8$ & $78 \pm 7$ \\
$T$ L,CO \% pred & $88 \pm 17$ & $63 \pm 16^{* * *}$ & $70 \pm 14^{* * *}$ & $85 \pm 15$ \\
$T$ L,CO-Hb \% pred & $94 \pm 15$ & $73 \pm 19^{* * *}$ & $76 \pm 15^{* * *}$ & $88 \pm 15$ \\
Hb g.100 $\mathrm{mL}^{-1}$ & $13.0 \pm 2.2$ & $10.4 \pm 1.4^{* * *}$ & $12.5 \pm 1.4$ & $13.8 \pm 0.8$ \\
\hline
\end{tabular}

Data are presented as mean \pm SD; Statistical comparisons: values at the time of maximum impairment (i.e. 3 months) and values at 12 months and $5 \mathrm{yrs}$ after BMT are compared with values pre-BMT. FVC: forced vital capacity; \% pred: per cent predicted; FEV1: forced expiratory volume in one second; TL,CO: transfer factor of the lung for carbon monoxide; TL,CO-Hb: transfer factor of the lung for carbon monoxide corrected for haemoglobin level; Hb: haemoglobin. *: $\mathrm{p}<0.05$; ***: $\mathrm{p}<0.001$, Bonferroni's correction for multiple comparisons. months (i.e. nadir), 1 yr and 5 yrs after BMT. FVC and FEV1 were significantly reduced after 3 months, but recovered after $1 \mathrm{yr}$. The corresponding increase in FEV1\% pred at 3 months reflects the restrictive pattern of the ventilatory impairment. Figure 2 shows the lung function variables expressed as a percentage of their baseline values. $T \mathrm{~L}, \mathrm{CO}-\mathrm{Hb}$ reached a nadir of $79 \pm 19 \%$ (mean \pm SD) of baseline after 3 months, was still significantly reduced by $82 \pm 15 \%$ of baseline after $1 \mathrm{yr}$, but recovered to $94 \pm 15 \%$ of baseline after $5 \mathrm{yrs}$. In patients with acute leukaemias, $T \mathrm{~L}, \mathrm{CO}-\mathrm{Hb}$ was restored to $98 \pm 14 \%$ of baseline after 5 yrs, as compared with $105 \pm 14 \%$ of baseline in patients with chronic leukaemia. In a multiple linear regression model, the association between a reduction in $T \mathrm{~L}, \mathrm{CO}-\mathrm{Hb}$ and acute leukaemia persisted 3 months after BMT (-10.3 \pm 4.6 ( $\beta$ coefficient $\pm \mathrm{SE}$ ), $\mathrm{p}=0.01$ ), but not after $1 \mathrm{yr}$ and $5 \mathrm{yrs}$. Smoking was associated with a decline in TL,CO-Hb 3 months $(-15.1 \pm 5.2, p=0.007)$ and 1 yr $(\beta$ coefficient $-9.4 \pm 4.5, p=0.04)$ after BMT, but no longer after 5 yrs. Sex, age and donor status were not significantly associated with reductions in $T \mathrm{~L}, \mathrm{CO}-\mathrm{Hb}$ at any time of follow-up. All patients (including the four with $\mathrm{OB}$ ) had normal chest radiographs at $1 \mathrm{yr}$ and $5 \mathrm{yr}$ follow-up. There were no cases of chronic pulmonary complications, other than $\mathrm{OB}$.

\section{Discussion}

The authors of the current study have previously shown a significant reduction in gas transfer throughout the 1st $\mathrm{yr}$ after allogeneic BMT, conditioned with BU/CY [17]. The major finding of the present study was that mean baseline lung function was restored after 5 yrs. The authors of the present study suggest that it may be premature to interpret a reduction in lung function $1 \mathrm{yr}$ after cytotoxic therapy as a permanent reduction, since it may be that the restoration process is slow and not yet fully completed.

For the entire study group, baseline lung function was normal, reflecting that the patients were young and otherwise healthy subjects. In general, baseline lung function was $>80 \%$ pred in patients both with acute and chronic leukaemias. The current authors suspected that prior chemotherapy would make the patients with acute leukaemias more susceptible to a reduction in lung function after BMT. The multivariate

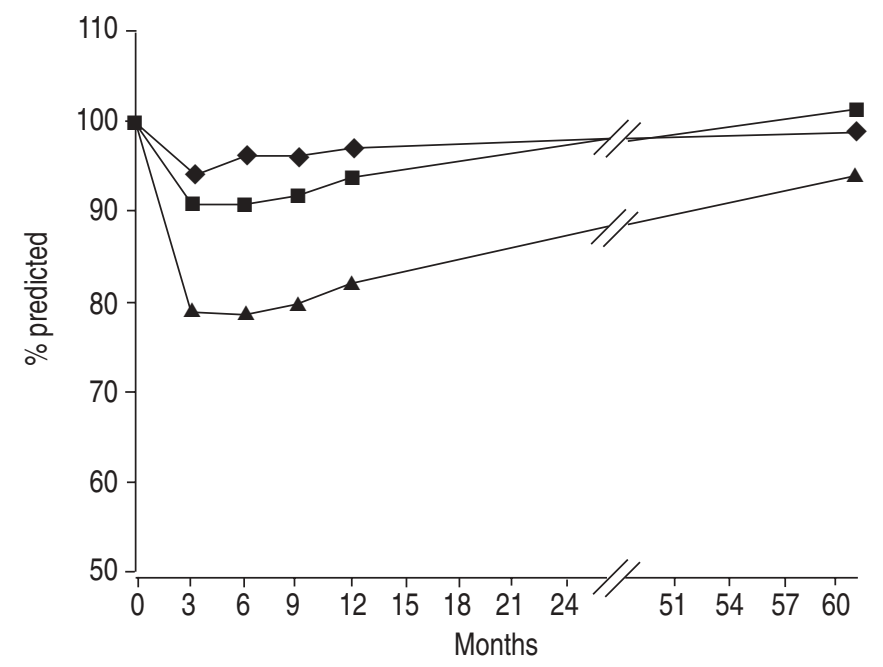

Fig. 2.-Changes in lung function after bone marrow transplantation expressed as a percentage of baseline values. $\bullet$ : forced vital capacity; $\boldsymbol{\mathbf { m }}$ : forced expiratory volume in one second; $\boldsymbol{\Lambda}$ : transfer factor of the lung for carbon monoxide corrected for haemoglobin level. 
analyses showed that the observed association between acute leukaemias and reduction in $\mathrm{TL}, \mathrm{CO}-\mathrm{Hb}$ at baseline persisted 3 months after BMT, but not thereafter. At the $5 \mathrm{yr}$ follow-up, mean TL,CO-Hb was restored in both groups. This implies that, although the patients who had received chemotherapy prior to BMT had significantly lower $\mathrm{TL}, \mathrm{CO}-\mathrm{Hb}$ both at baseline and 3 months after BMT, they did not suffer further decline and they obtained nearly the same level of recovery (compared with baseline) as the patients with chronic leukaemias.

The authors of the present study found that smoking was a significant predictor for a reduction in $T \mathrm{~L}, \mathrm{CO}-\mathrm{Hb}$ at baseline and 3 months and $1 \mathrm{yr}$ after BMT, but the current study failed to demonstrate a similar association after $5 \mathrm{yrs}$. This may partly be explained by changes in smoking habits over the 5 yrs. No patients started to smoke after BMT, but some of the smokers had quit for shorter or longer periods, and at 5 yrs follow-up, they described themselves as occasional or periodic smokers rather than daily (i.e. current) smokers. Since smoking habits were difficult to categorise in a standardised manner at that time, the current study also chose to use the information obtained at inclusion for the 5-yr analysis. However, this implies a bias towards underestimating an effect of smoking, and the results should, therefore, be interpreted with due caution.

The present study consisted of a nonirradiated patient population, all conditioned with BU/CY. Since 1989, BU/CY has been the standard myeloablative therapy for patients undergoing allogeneic BMT for malignant blood disorders at the institution where the current study was performed, and the regimen is still in current use. Pretransplant conditioning with high-dose BU/CY was introduced in the early 1980s as an alternative to the established TBI/CY regimen that had been considered the treatment of choice since the 1970s [13, 14]. The development of the new preparative BU/CY regimen was motivated by a desire to reduce radiation-related toxicity and improve long-term survival. However, controversy still persists concerning the optimal conditioning regimen prior to allogeneic BMT. Some older studies indicated that interstitial pneumonitis occurred more frequently among patients treated with TBI than those treated with BU [23, 24], but more recent meta-analysis [25] and long-term follow-up of four randomised studies have concluded that late pulmonary complications occur equally after both conditioning regimens [26]. The decline in $\mathrm{TL}, \mathrm{CO}-\mathrm{Hb}$ observed in the nonirradiated patients was comparable to that reported in patients conditioned with TBI $[9,27]$. However, the associated development of OB after allogeneic BMT remains to be proven. A randomised long-term study by the Nordic Bone Marrow Transplantation Group reported a significantly increased risk of $\mathrm{OB}$ in patients conditioned with BU/CY as compared with those conditioned with TBI/CY [28], but the subsequent report of four randomised studies did not confirm the finding [26]. The prevalence of $\mathrm{OB}$ in subjects in the current study was comparable to that observed in other studies, applying conditioning regimens with and without TBI [2].

In conclusion, allogeneic bone marrow transplantation with busulphan/cyclophosphamide conditioning is associated with a significant decline in gas transfer throughout the first year after treatment. However, after 5 yrs, recovery to baseline has generally been obtained. Acute leukaemias and smoking, prior to bone marrow transplantation, are independent risk factors for a reduction in gas transfer at baseline and during the 1st yr after bone marrow transplantation, but after 5 yrs no risk factors can be identified. In general, allogeneic bone marrow transplantation with busulphan/cyclophosphamide may be considered safe therapy with respect to long-term pulmonary function, with the exception of patients who develop chronic graft versus host disease and are at risk of obliterative bronchitis.
Acknowledgements. The authors thank K.F. Frøslie, Dept of Biostatistics, for statistical assistance.

\section{References}

1. Kolb H-J, Poetscher C. Late effects after allogeneic bone marrow transplantation. Curr Opin Hematol 1997; 4: 401-407.

2. Socié G, Salooja N, Cohen A, et al. Nonmalignant late effects after allogeneic stem cell transplantation. Blood 2003; 101: 3373-3385.

3. Ghalie R, Szidon JP, Thompson L, Nawas YN, Dolce A, Kaizer H. Evaluation of pulmonary complications after bone marrow transplantation: the role of pretransplant pulmonary function tests. Bone Marrow Transplant 1992; 10: 359-365.

4. Soubani AO, Miller KB, Hassoun PM. Pulmonary complications of bone marrow transplantation. Chest 1996; 109: 1066-1077.

5. Ho VT, Weller E, lee SJ, Alyea EP, Antin JH, Soiffer RJ. Prognostic factors for early severe pulmonary complications after hematopoietic stem cell transplantation. Biol Blood Marrow Transplant 2001; 7: 223-229.

6. Badier M, Delpierre S, Vanuxem P, Blaise D, Maraninchi D. Pulmonary function changes 100 days and one year after bone marrow transplantation. Bone Marrow Transplant 1993; 12: 457-461.

7. Prince DS, Wingard JR, Saral R, Santos GW, Wise RA. Longitudinal changes in pulmonary function following bone marrow transplantation. Chest 1989; 96: 301-306.

8. Palmas A, Teferi A, Myers JL, et al. Late-onset noninfectious pulmonary complications after allogeneic bone marrow transplantation. Br J Haematol 1998; 100: 680-687.

9. Gore EM, Lawton CA, Ash RC, Lipchik RJ. Pulmonary function changes in long-term survivors of bone marrow transplantation. Int J Radiat Oncol Biol Phys 1996; 36: 67-75.

10. Chiou TJ, Tung SL, Wang WS, et al. Pulmonary function changes in long-term survivors of chronic myelogenous leukaemia after allogeneic bone marrow transplantation: a Taiwan experience. Cancer Invest 2002; 20: 880-888.

11. Duncker C, Dohr D, von Harsdorf S, et al. Non-infectious lung complications are closely associated with chronic graft-versus-host disease: a single centre study of incidence, risk factors and outcome. Bone Marrow Transplant 2000; 25 : 1263-1268.

12. Folz RJ. Mechanisms of lung injury after bone marrow transplantation. Am J Respir Cell Mol Biol 1999; 20: 10971099.

13. Santos GW, Tutschka PJ, Brookmeyer R, et al. Marrow transplantation for acute nonlympholcytic leukemia after treatment with busulfan and cyclophosphamide. $N$ Engl J Med 1983; 309: 1347-1353.

14. Tutschka PJ, Copelan EA, Klein JP. Bone marrow transplantation for leukaemia following a new busulphan and cyclophosphamide regimen. Blood 1987; 70: 1382-1388.

15. Cooper JAD, White DA, Matthay RA. Drug-induced pulmonary disease. Cytotoxic drugs. Am Rev Respir Dis 1986; 133: 321-340.

16. Philit F, Wiesendanger $\mathrm{T}$, Archimbaud E, Mornex J-F, Brune J, Cordier J-F. Post-transplant obstructive lung disease ("bronchiolitis obliterans"): a clinical comparative study of bone marrow and lung transplant patients. Eur Respir J 1995; 8: 551-558.

17. Lund MB, Kongerud J, Brinch L, Evensen SA, Boe J. Decreased lung function in one year survivors of allogeneic bone marrow transplantation conditioned with high-dose busulphan and cyclophosphamide. Eur Respir J 1995; 8: 1269-1274.

18. Ferrara JL, Deeg HJ. Graft-versus-host disease. $N$ Engl J Med 1991; 324: 667-674.

19. American Thoracic Society. Standardization of spirometry 1987 update. Am Rev Respir Dis 1987; 136: 1285-1298. 
20. American Thoracic Society. Single breath carbon monoxide diffusing capacity (transfer factor). Recommendations for a standard technique. Am Rev Respir Dis 1987; 136: 1299-1307.

21. Cotes JE, Dabbs JM, Elwood PC, Hall AM, McDonald A, Saunders MJ. Iron deficiency anaemia: its effect on transfer factor for the lung (diffusing capacity) and ventilation and cardiac frequency during submaximal exercise. Clin Sci 1972; 42: 325-335.

22. Quanjer PH, Dalhuijsen A, van Zomren BC. Summary equations of reference values. Clin Respir Physiol 1983; 19: 45-51.

23. Morgan M, Dodds A, Atkinson K, Szer J, Downs K, Biggs $\mathrm{J}$. The toxicity of busulphan and cyclophosphamide as the preparative regimen for bone marrow transplantation. $\mathrm{Br}$ J Haematol 1991; 77: 529-534.

24. Ringden $\mathrm{O}$, Labopin $\mathrm{M}$, Tura $\mathrm{S}$, et al. comparison of busulphan versus total body irradiation combined with cyclophosphamide as conditioning for autograft or allograft bone marrow transplantationin patients with acute leukaemia. Br J Haematol 1996; 93: 637-645.
25. Hartman A-R, Williams SF, Dillon JJ. Survival, disease-free survival and adverse effects of conditioning for allogeneic bone marrow transplantation with busulphan/ cyclophosphamide versus total body irradiation: a meta-analysis. Bone Marrow Transplant 1998; 22: 439-443.

26. Socié G, Clift RA, Blaise D, et al. Busulphan plus cyclophosphamide compared with total-body irradiation plus cyclophosphamide before marrow transplantation for myeloid leukaemia: long-term follow-up of 4 randomized studies. Blood 2001; 98: 3569-3574.

27. Marras TK, Szalai JP, Chan CK, Lipton JH, Messner HA, Laupacis A. Pulmonary function abnormalities after allogeneic marrow transplantation: a systematic review and assessment of an existing predictive instrument. Bone Marrow Transplant 2002; 30: 599-607.

28. Ringden $\mathrm{O}$, Remberger M, Ruutu $\mathrm{T}$, et al. Increased risk of chronic graft-versus-host disease, obstructive bronchiolitis, and alopecia with busulfan versus total body irradiation: long-term results of a randomized trial in allogeneic marrow recipients with leukaemia. Blood 1999; 93: 2196-2201. 